\title{
Compatibility by a Nonisothermal Kinetic Study of Azathioprine Associated with Usual Excipients in the Product Quality Review Process
}

\author{
Carolina R. G. Silva, ${ }^{a}$ Silvia L. Fialho, ${ }^{b}$ Jamile Barbosa, ${ }^{b}$ Bárbara C. R. Araújo, ${ }^{a}$ \\ Guilherme Carneiro, ${ }^{c}$ Rita C. O. Sebastião, ${ }^{\circledR a}$ Wagner N. Mussel, ${ }^{\circledR a}$ Maria I. Yoshida ${ }^{\circledR a}$ \\ and Maria B. de Freitas-Marques ${ }^{\circledR *, a, c}$ \\ ${ }^{a}$ Departamento de Química, Universidade Federal de Minas Gerais, Av. Antonio Carlos, 6627, \\ Campus Pampulha, 31270-901 Belo Horizonte-MG, Brazil \\ ${ }^{b}$ Pesquisa e Desenvolvimento, Fundação Ezequiel Dias, Rua Conde Pereira Carneiro, 80, \\ Gameleira, 30510-010 Belo Horizonte-MG, Brazil \\ 'Departamento de Farmácia, Faculdade de Biologia e Ciências da Saúde, \\ Universidade Federal dos Vales do Jequitinhonha e Mucuri, Campus JK, \\ Rodovia MGT 367, km 583, 5000, Alto da Jacuba, 39100-000 Diamantina-MG, Brazil
}

\begin{abstract}
Azathioprine is an immunosuppressive drug for several inflammatory disorders. Due to its clinical relevance, to explore the solid-state properties for excipient compatibility in the product quality review process is essential. Fourier transform infrared spectroscopy, powder X-ray diffraction and thermal analysis (thermogravimetry/derivative thermogravimetry (TG/DTG), differential thermal analysis (DTA), and differential scanning calorimetry (DSC)) were applied. The compatibility studies evidenced that starch pregelatinized, colloidal silicon dioxide, and talc are fully compatible with azathioprine. However, stearic acid, magnesium stearate, and mannitol are incompatible after heat supply at temperatures easily reached by industrial processing. The nonlinear Vyazovkin isoconversional treatment performed the kinetic study of the thermal degradation. The activation energies were determined to clarify the influence of each excipient on the thermal drug stability, an essential procedure in the pharmaceutical development, and all over the commercial live span, in Good Manufacturing Practices.
\end{abstract}

Keywords: immunosuppressive drug, Good Manufacturing Practices, solid-state properties, activation energy, Vyazovkin method, Fukui function

\section{Introduction}

Safety and efficiency are the primary concern of the Pharmaceutical industry. ${ }^{1,2}$ To inspect the global production, the health supervision regulatory agencies publish guidelines ${ }^{3,4}$ to ensure the quality of the final product, promoting public health, as a set of procedures in the Good Manufacturing Practices (GMP) on the Pharmaceutical Inspection Co-operation Scheme (PIC/S).

For tablets, the excipients have to be carefully selected, since they cannot show pharmacological activity. Besides, some compounds can modify diffusion and adhesion properties, which disturb the biopharmaceutical behavior of the active pharmaceutical ingredient (API) and formulation stability itself. ${ }^{1}$

*e-mail: betanialf@hotmail.com
Solid-state physical and chemical interactions can modify pharmacological activity, as well as the stability of the drug product. ${ }^{5}$ To maintain the physicochemical stability of any pharmaceutical formulation, the melting point, the crystallinity, the hydration levels, the hygroscopic behavior, and the powder particle morphology of all components have to be preserved. ${ }^{6}$ The characteristics also relate to the water solvability or biological fluids, defining the biopharmaceutical properties. Therefore, adequate tools for data treatment obtained by process analytical technology (PAT) inserted in the production is crucial for GMP. ${ }^{7}$

According to the GMP guidance, the pharmaceutical dosage protocol should contain all raw materials, accurately characterized, as well as the process instructions with any transformation in the composition during the manufacturing procedure. ${ }^{4,8}$ Therefore, it is strictly necessary to know the nature of the interactions between API and excipients in 
the formulation. ${ }^{2,59}$ Thermal analysis has commonly been applied for this purpose. ${ }^{10-16}$ It requires a small sample amount with a robust screening on thermal behavior, indicating any variation in transition enthalpies, thermal stability, and temperature of decomposition. ${ }^{17,18}$

In the literature, ${ }^{19}$ descriptions of the thermal behavior of azathioprine (AZA), with few or no information concerning its compatibility with usual pharmaceutical excipients, are constant occurrences. Derived from thioguanine, AZA (1-methyl-4-nitro-5-imidazolyl), a purine-mimic antimetabolite, acts as an immunosuppressive drug. The API is still used for inflammatory disorders, including rheumatic diseases, systemic lupus erythematosus, dermatomyositis, polymyositis, systemic sclerosis, systemic vasculitis, and for the prevention of organ transplant rejection. ${ }^{20,21}$

Pharmaceutical products containing AZA already include excipients as mannitol, microcrystalline cellulose, pregelatinized starch, sodium starch glycolate, magnesium stearate, stearic acid, talc, hypromellose, macrogol, and lactose monohydrate. Crospovidone and some pigments are still in use. Among the requirements of the pharmacotechnical characteristics for the excipients, the compatibility study with the API is essential for the safe pharmacological activity and formulation stability assurance.

In this context, the GMP requires the product quality review periodically to verify the suitability of the production processes and conformity of the raw materials, which are critical aspects of the quality of the finished product. ${ }^{4}$ This practice is one of the practical pharmacovigilance actions adopted by the manufacturing industries. Product quality reviews cover the entire production chain, and the earlier the monitored phase, the higher the chance of controlling deviations and successful corrective actions. The importance of assessing the compatibility of APIexcipients before and after registration of the drug product is pointed out.

Due to the clinical relevance of AZA, the present work explores the solid-state properties to attest to the compatibility with the most used excipients for oral delivery systems as a tool for product quality review. Among the used excipients, the chosen ones are pregelatinized starch (diluent, binder), colloidal silicon dioxide (lubricant), talc (lubricant), microparticulate stearic acid (lubricant), magnesium stearate (lubricant), and mannitol M100 (diluent). ${ }^{22}$ The kinetics of thermal behavior is also studied in full agreement with International Confederation for Thermal Analysis and Calorimetry (ICTAC) ${ }_{, 2}^{23}$ using thermogravimetry (TG) data at four heating rates to explore the kinetics of AZA-excipients interaction. The Vyazovkin method ${ }^{24-26}$ was adopted to determine the activation energy $(\mathrm{Ea})$ as a function of system conversion. ${ }^{27-32}$ It is possible to determine the kinetic triplet (activation energy, frequency factor and kinetic models) using together with the isoconversional methods, specific software as TKS-SP 1.0 and 2.0. ${ }^{33,34}$ However, in this work the Vyazovkin isoconversional method was adopted to determine the activation energy, using a homemade computer program developed by the research group in Matlab language..$^{35}$ This approach is an innovative to data treatment in PAT for compatibility study in pharmaceutical industry. AZA is already commercialized, nevertheless, still in constant pharmacovigilance all over the life span, and it is essential to product quality review recommended by GMP. ${ }^{4}$

\section{Experimental}

\section{Samples}

Azathioprine (AZA, Microbiológica Química e Farmacêutica, Rio de Janeiro, Brazil, lot: AP.006.2015), pregelatinized starch (ST, Colorcon do Brasil Ltda, São Paulo, Brazil, lot: IN524827), colloidal silicon dioxide $\left(\mathrm{SiO}_{2} \mathrm{c}, \mathrm{Cabot}\right.$ - Creating What Matters, Boston, USA, lot: 3352341), talc (TA, Magnesita, Contagem, Brazil, lot: N-123691-0), micro pulverized stearic acid (SA, Stearinerie Dubois Fils, Orléans, France, lot: 12081001), magnesium stearate (MS, Peter Greven, Bad Münstereifel, Germany, lot: C41827) and mannitol M100 (MA, Merck, Rio de Janeiro, Brazil, lot: M754494) were used. Binary mixtures 1:1 (m/m) AZA:excipient mixtures were obtained, comminuted and homogenized in a mortar and pestle.

\section{Fourier transform infrared spectroscopy (FTIR)}

The FTIR analysis in an attenuated total reflection (ATR) setup uses a PerkinElmer Spectrum One, in the range of $600-4000 \mathrm{~cm}^{-1}$ at room temperature with a resolution of $4 \mathrm{~cm}^{-1}$.

\section{Powder X-ray diffraction (PXRD)}

PXRD data were collected in a Shimadzu diffractometer, XRD-7000, under $40 \mathrm{kV}, 30 \mathrm{~mA}$, using $\mathrm{Cu} \mathrm{K} \alpha(\lambda=1.54056 \AA)$, measured from $5-40^{\circ} 2 \theta$ with a step size of $0.02^{\circ}$ and a time constant of $1.2 \mathrm{~s} \mathrm{step}^{-1}$, using a graphite monochromator, in a parallel focusing geometry under $30 \mathrm{rpm}$ to prevent any remained preferred orientation. Mercury ${ }^{\circledast}$ software from Cambridge Crystallographic Data Center (CCDC) was used to calculate the intermolecular energies along with the unit cell axes. For Rietveld fitting analysis the considered angular range was 5 up to $50^{\circ} 2 \theta$. 


\section{Thermal analysis}

Thermogravimetry (TG) and derivative thermogravimetry (DTG) with simultaneous differential thermal analysis (DTA) were conducted in a Shimadzu DTG60. All conducted standard methods for thermal stability follow the procedures of the American Society for Testing and Materials (ASTM), E2550-17, ${ }^{36}$ the heating rate at $10{ }^{\circ} \mathrm{C} \mathrm{min}{ }^{-1}$ at the room temperature up to $600{ }^{\circ} \mathrm{C}$, under a controlled atmosphere of $50 \mathrm{~mL} \mathrm{~min}^{-1}$ of nitrogen $\left(\mathrm{N}_{2}\right)$ and air in an alumina crucible with sample mass of about $2.5 \mathrm{mg}$.

Conducted differential scanning calorimetry (DSC) analysis follow the standardization by ASTM E53712. ${ }^{37}$ The equipment used was a DSC60 Shimadzu, calibrated with indium (melting point: $\mathrm{T}_{\text {onset }}=156.63{ }^{\circ} \mathrm{C}$, $\Delta \mathrm{H}_{\text {fus }}=28.45 \mathrm{~J} \mathrm{~g}^{-1}$ ), under a dynamic nitrogen atmosphere,

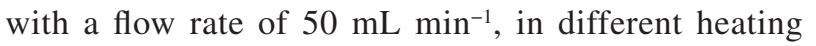
rates from room temperature up to $300{ }^{\circ} \mathrm{C}$, enclosed in a partially closed aluminum crucible. Samples about $1.5 \mathrm{mg}$ were accurately weighted. The $\mathrm{T}_{\text {onset }}$ characteristic of the phenomena corresponds to the extrapolated temperature, calculated based on the thermal phenomenon peak asymmetry, and the $\Delta \mathrm{H}$ corresponds to the involved enthalpy change for the event, in $\mathrm{J} \mathrm{g}^{-1}$. The expressed heat of fusion given by means of $\Delta \mathrm{H}_{\text {fus }}{ }^{38}$ Calculated enthalpy data uses a TA-60 software version 2.20.

\section{Nonisothermal kinetic study}

The kinetic study of the thermal decomposition was performed under dynamic analysis. The experimental TG data at rates $(\beta)$ of $6,8,10$, and $12{ }^{\circ} \mathrm{C} \min ^{-1}$ were used to calculate the degree of conversion, $\alpha$, of AZA and AZA systems, as $\alpha \mathrm{i}=\frac{\mathrm{m}_{\mathrm{i}}-\mathrm{m}_{\mathrm{t}}}{\mathrm{m}_{\mathrm{i}}-\mathrm{m}_{\mathrm{f}}}$, being $\mathrm{m}_{\mathrm{i}}$ the initial mass, $\mathrm{m}_{\mathrm{t}}$ the mass in a time $t$ and $m_{\mathrm{f}}$ the final mass. For the study of the AZA and respective binary systems, we apply the nonlinear Vyazovkin method. ${ }^{30}$

\section{Results and Discussion}

The $\mathrm{C}-\mathrm{H}$ stretching vibrations bands occurring at 3194 , $3122,3108 \mathrm{~cm}^{-1}$, are characteristic for $\mathrm{C}-\mathrm{H}$ in aromatics; the AZA molecule has one $\mathrm{CH}_{3}$ group, so three stretching vibrations are expected. However, only two asymmetric C-H stretching bands are still observed at 2971 and $2930 \mathrm{~cm}^{-1}$, while the $\mathrm{C}-\mathrm{H}$ symmetric stretching vibrations are visible at $2806 \mathrm{~cm}^{-1}$, the asymmetric stretch is usually at higher wavenumber than the symmetric one. ${ }^{39,40} \mathrm{As}$ observed, the ring $\mathrm{C}=\mathrm{N}$ and $\mathrm{C}=\mathrm{C}$ stretching vibrations occur at 1497 and $1481 \mathrm{~cm}^{-1}$, respectively; $\mathrm{N}-\mathrm{O}$ symmetric and asymmetric stretch are experimentally observed at 1573 and $1300 \mathrm{~cm}^{-1}$; C-S stretching vibrations are found at $640 \mathrm{~cm}^{-1} .{ }^{40}$ The vibrational spectra of AZA (Figure 1) showed the same bands and relative intensities when compared to the described in the literature. ${ }^{19,41,42}$

FTIR was also used to evaluate alterations in the AZA functional groups, and the present study used excipients for the compatibility evaluation, so the band shifts and observed intensities suggest some interaction. Figure 2 shows the spectra of AZA, ST, AZA + ST binary, $\mathrm{SiO}_{2} \mathrm{c}, \mathrm{AZA}+\mathrm{SiO}_{2} \mathrm{c}$ binary, TA, AZA + TA binary, MA, AZA + MA binary,

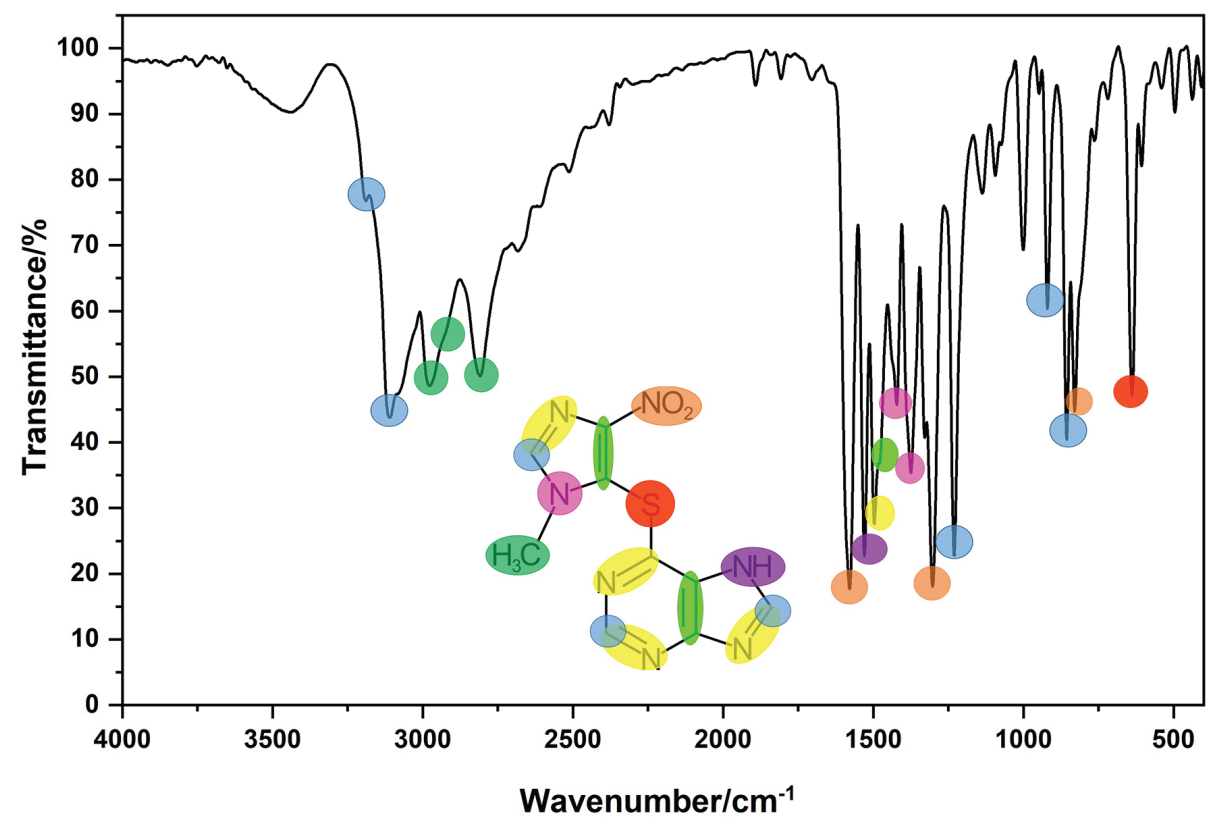

Figure 1. Fourier transform infrared spectra (ATR) of azathioprine. The colors indicate the assignments corresponding to the functions in the molecule. 
SA, AZA + SA binary, MS, and AZA + MS binary. The binary mixtures spectra (blue) correspond to the vibrational contribution of each system component (black) individually, except for AZA + MA, in the range between $3400-3100 \mathrm{~cm}^{-1}$, where MA characteristic bands are absent (circled in small dot).

Figure $3 \mathrm{a}$ indicates the diffraction pattern of AZA fitted by the Rietveld analysis and its crystalline habit. The AZA compound is crystalline; the Rietveld's refinement indicates that the molecule crystallizes over the $\mathrm{P} 2{ }_{1} \mathrm{C} / 1$ space group. The lattice parameters are $a=4.2030 \pm 0.0009 \AA$, $b=30.834 \pm 0.007 \AA, c=7.552 \pm 0.002 \AA, \alpha=\gamma=90.00^{\circ}$, $\beta=106.31 \pm 0.01^{\circ}$. The diffraction pattern identifies the sample as the polymorph form I. ${ }^{19}$ Azathioprine crystal habit showing the Miller index identification is in Figure $3 b$.

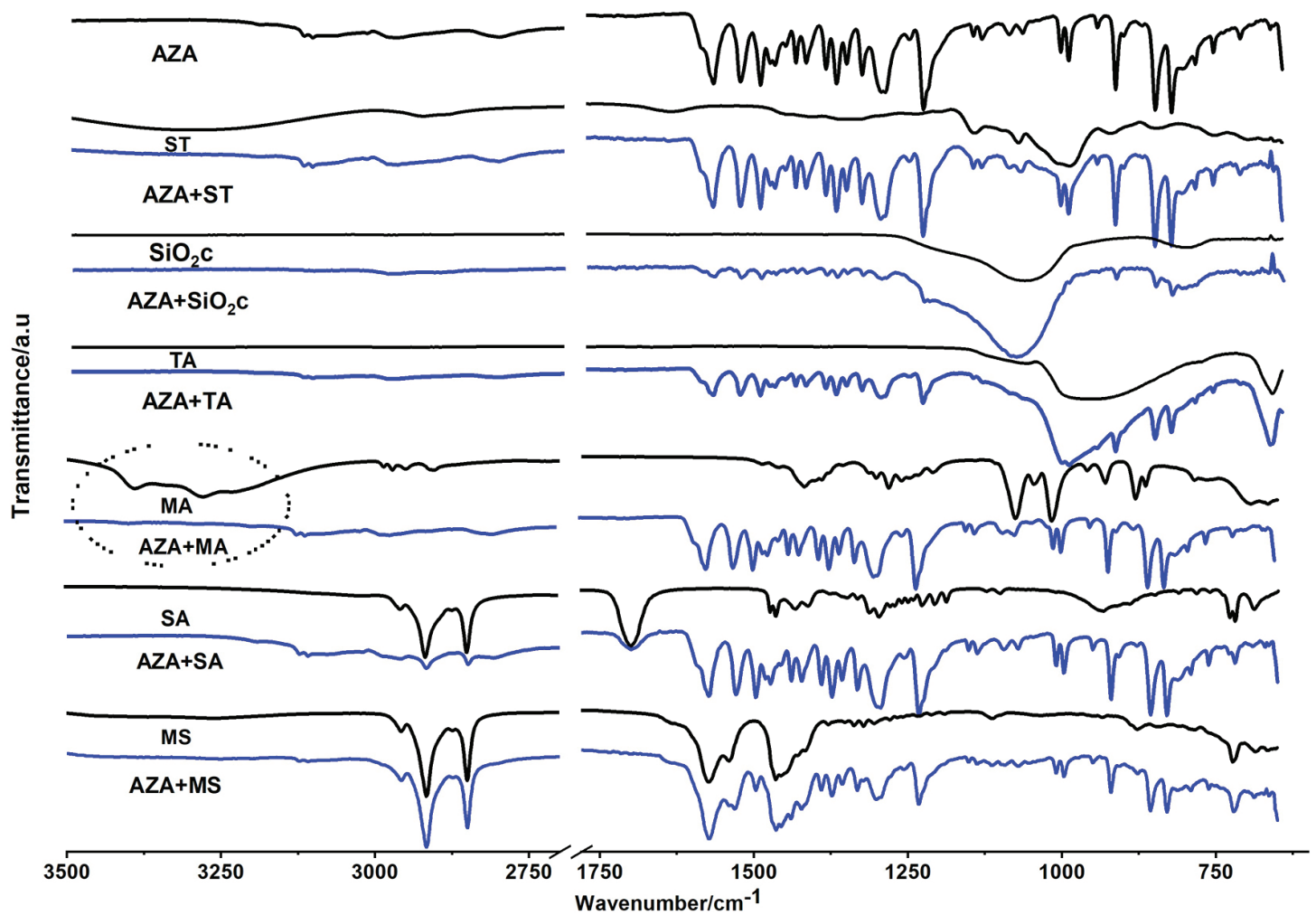

Figure 2. Fourier transform infrared spectra (ATR) of azathioprine (AZA), starch (ST), AZA + ST binary, colloidal silicon dioxide $\left(\mathrm{SiO}_{2} \mathrm{c}\right), \mathrm{AZA}+\mathrm{SiO}_{2} \mathrm{c}$ binary, talc (TA), AZA + TA binary, mannitol (MA), AZA + MA binary, stearic acid (SA), AZA + SA binary, magnesium stearate (MS) and AZA + MS binary. The broken $x$-axis at $2700-1780 \mathrm{~cm}^{-1}$ stands for better viewing.

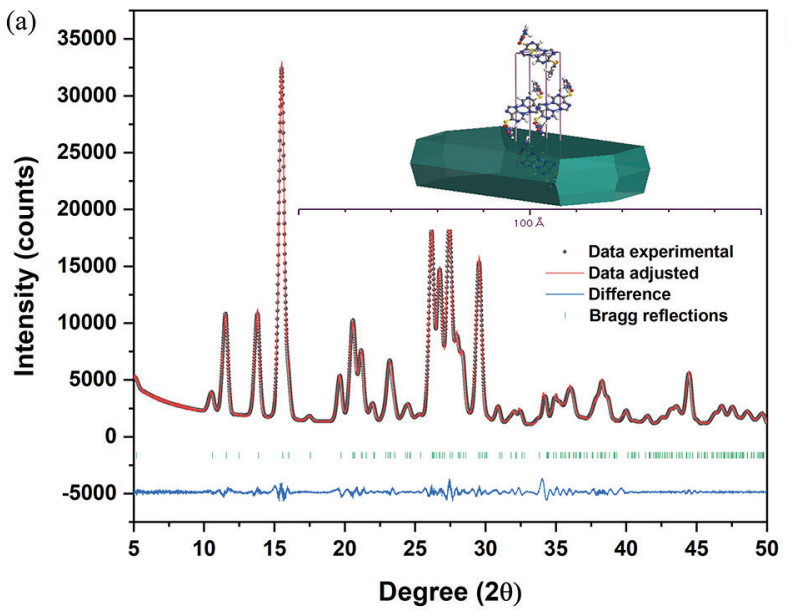

(b)

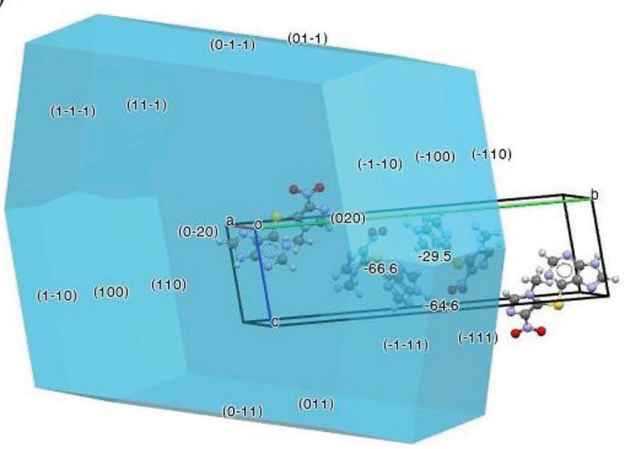

Figure 3. (a) Diffraction pattern of azathioprine fitted by the Rietveld analysis. The green sticks correspond to the permitted Bragg reflections for the angular range of 5 up to $50^{\circ} 2 \theta$, black dots correspond to the experimental data points, the red line corresponds to the Rietveld fitting, and the blue line corresponds to the difference between experimental and fitted point; (b) azathioprine crystal habit showing the Miller index identification in each face. 
For comparison purposes, the PRXD is confronted before (in static mode), just after physical mixing of the phases and after some absorbed energy, as observed at comminution, pressing, encapsulation following up any physical-chemical visible change to check all the studied samples (Figure 4). The AZA peaks at 11.0, 13.8, 15.5, 26.1, 26.7, 27.4, and $29.5^{\circ} 2 \theta$ were highlighted for comparison. The diffractions of the binary mixtures (Figure 4, blue), in static mode before any amount of energy absorbed by the system, corresponds to the overlap of the individual diffractions, for the active pharmaceutical ingredient and the excipients alone. Variations in relative intensity of the peaks, appearance, or disappearance of reflection planes may evidence some drug-excipient interaction in the X-ray diffraction associated with peak or atoms displacements. There were no variations in the diffractions patterns that could attest incompatibilities between AZA and the excipients just by mixing the individual components, with no external influence, heat, comminution, pressure, or any sort of physical processing.

The thermal behavior study was carried out by TG/DTG simultaneous DTA and DSC. Covaci et al. ${ }^{19}$ studied AZA only in a unique atmosphere and the single heating ratio. According to ASTM, ${ }^{36,37}$ the recommendation for thermal behavior evaluation includes an inert atmosphere, a reactive or self-generated atmosphere, and different heating rates. At the present research, TG/DTA curves were performed under a dynamic atmosphere in $\mathrm{N}_{2}$ and air at $50 \mathrm{~mL} \mathrm{~min}^{-1}$, to check the drug behavior under the oxidative atmosphere, a piece of complementary and essential information about stability. Under an inert atmosphere, $\mathrm{N}_{2}$ (Figure 5, left), and under air, oxidative atmosphere (Figure 5, right), AZA showed similar behavior evidencing thermal stability up to ca. $258{ }^{\circ} \mathrm{C}$ for both atmospheres. The decomposition process begins with a mass loss effect in three-step as observed in TG curve (red), confirmed in DTG (pink): in the first step, ca. $258-285^{\circ} \mathrm{C}$, loss ca. $16 \%$; in the second step, loss $11.5 \%$ (ca. $286-388^{\circ} \mathrm{C}$ ). For the third decomposition step (ca. $389-600{ }^{\circ} \mathrm{C}$ ), there is a different behavior: under the $\mathrm{N}_{2}$ atmosphere, there is a $21 \%$ mass loss; on the other hand, under air, it occurs $40.5 \%$ mass loss. This difference is expected, taking into account the oxidizing effect of the atmosphere at high temperatures, which enhances the decomposition. The DTA curves (Figure 5, dark cyan) exhibit baseline modifications, a fusion phenomenon, as described below for DSC analysis and decomposition steps, as expected.

According to the ASTM E537-12, ${ }^{37}$ a heating rate of 10 to $20^{\circ} \mathrm{C} \mathrm{min}^{-1}$ is considered usual for testing. However, if a specific exothermal phenomenon immediately follows

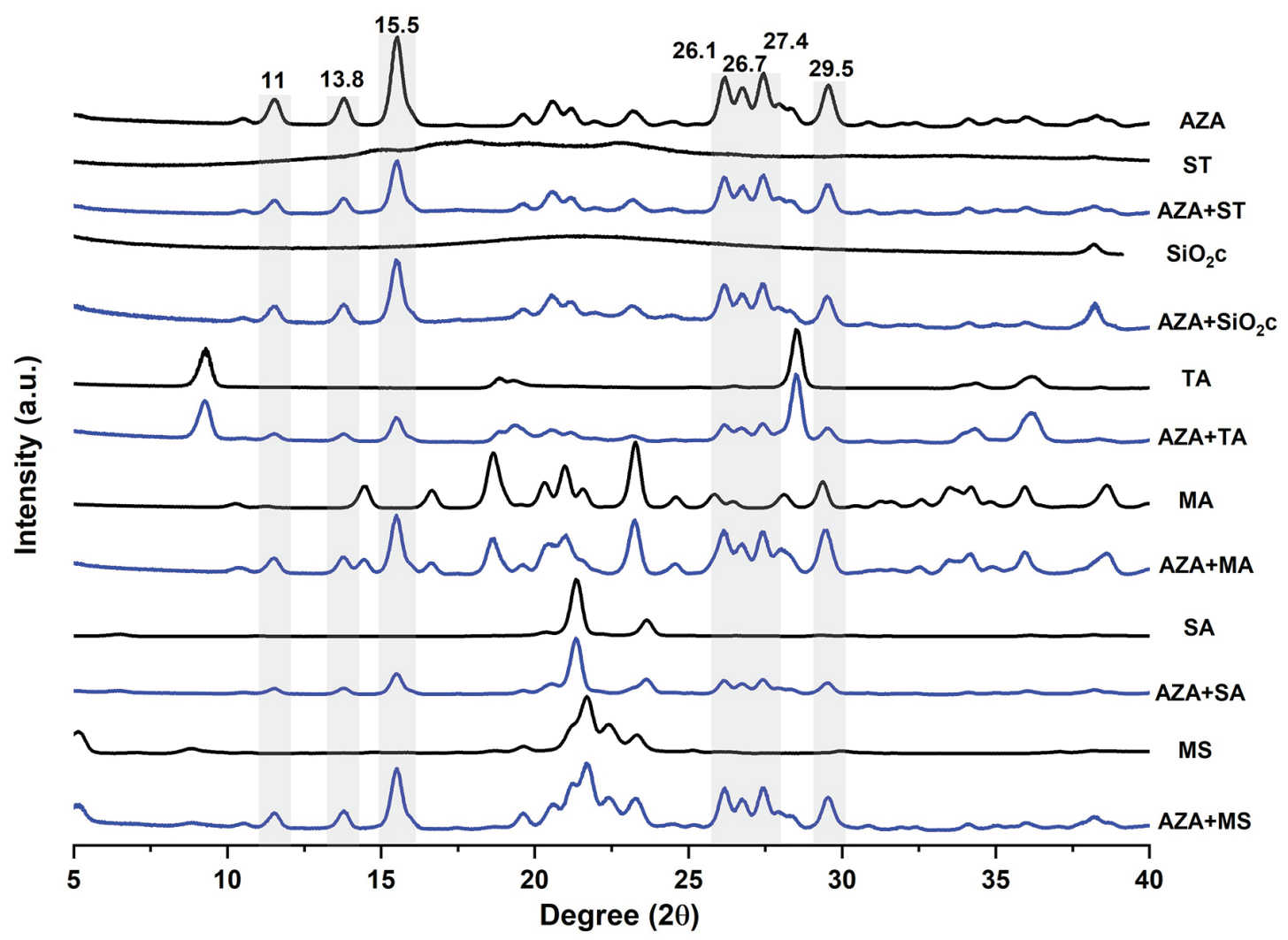

Figure 4. Diffraction pattern of azathioprine (AZA), starch (ST), AZA + ST binary, colloidal silicon dioxide $\left(\mathrm{SiO}_{2} \mathrm{c}\right), \mathrm{AZA}+\mathrm{SiO}_{2} \mathrm{c}$ binary, talc $(\mathrm{TA})$, AZA + TA binary, mannitol (MA), AZA + MA binary, stearic acid (SA), AZA + SA binary, magnesium stearate (MS) and AZA + MS binary. 

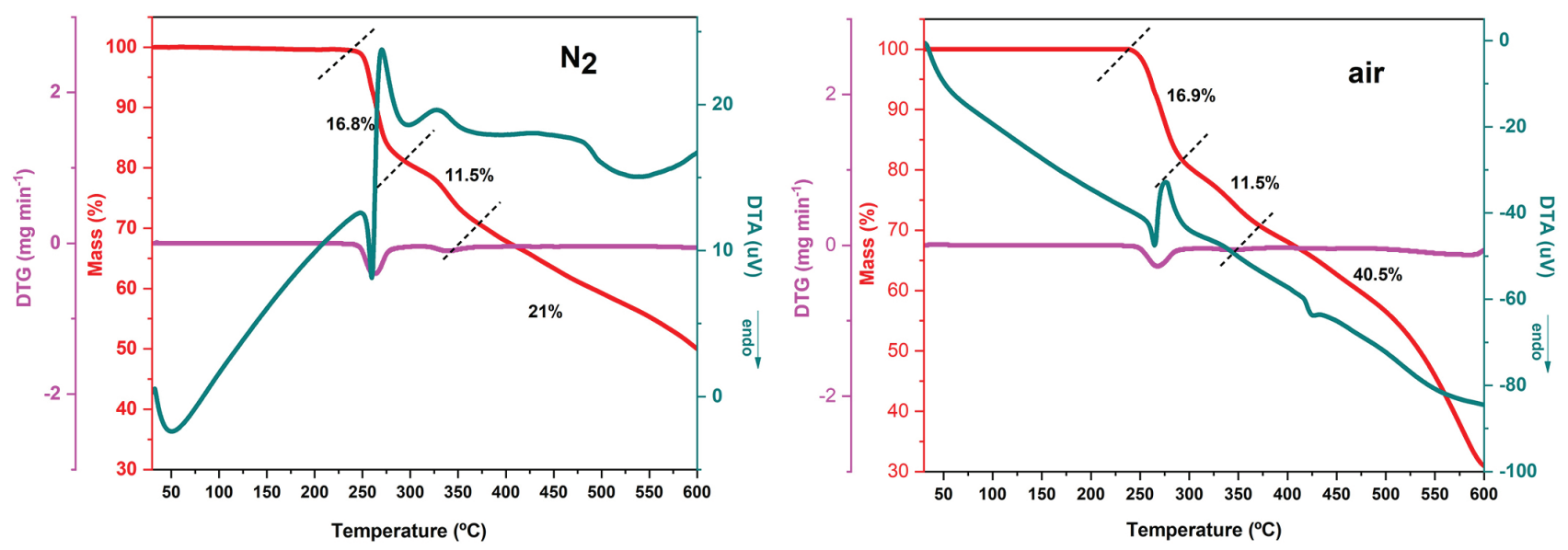

Figure 5. Thermogravimetry (red)/derivative thermogravimetry (pink) with simultaneous differential thermal analysis (dark cyan) curves of azathioprine under a dynamic atmosphere in nitrogen (left) and air (right) at $50 \mathrm{~mL} \mathrm{~min}^{-1}$.

an endothermic response, a lower heating rate of 2 up to $6{ }^{\circ} \mathrm{C} \mathrm{min}-1$ is mandatory based on the laboratory good practices. Therefore, the enthalpy of AZA was measured at different heating rates of $2,6,10,20$, and $50{ }^{\circ} \mathrm{C} \mathrm{min}^{-1}$. Figure 6 shows the sample heat evolution in the range of $30-300{ }^{\circ} \mathrm{C}$. By the increase of the heating rate, the thermal phenomena represented by DSC curves slightly shift to higher temperatures, due to the speed variation of the detection, characteristic of the equipment. ${ }^{25,43}$

At the slow heating rates, the changes occur gradually, and, due to the intensity of the thermal phenomenon, the detector may not distinguish them as an isolated phenomenon. For instance, in the DSC curve at $2{ }^{\circ} \mathrm{C} \mathrm{min}^{-1}$, it was not possible to observe the AZA fusion. It is noteworthy the change of the baseline ca. $230{ }^{\circ} \mathrm{C}$ with heat released, characteristic of thermal decomposition. For the heating rates of $6,10,20$, and $50{ }^{\circ} \mathrm{C} \mathrm{min}{ }^{-1}$, it was observed one endothermic response corresponding to AZA fusion, followed by another phenomenon identified as their exothermal decomposition. It is observable the physical transformation in the range of $249-272{ }^{\circ} \mathrm{C}\left(\mathrm{T}_{\text {onset }}\right)$ with enthalpy variation between $\Delta \mathrm{H}_{\text {fus }}=37-107 \mathrm{~J} \mathrm{~g}^{-1}$. When the sample reaches the thermal phenomena, the high heating rate prevents to distinguish the events, sometimes leading to enthalpy overestimation, as occurred in the AZA DSC curve at $50{ }^{\circ} \mathrm{C} \mathrm{min}^{-1}$. This result was reported by

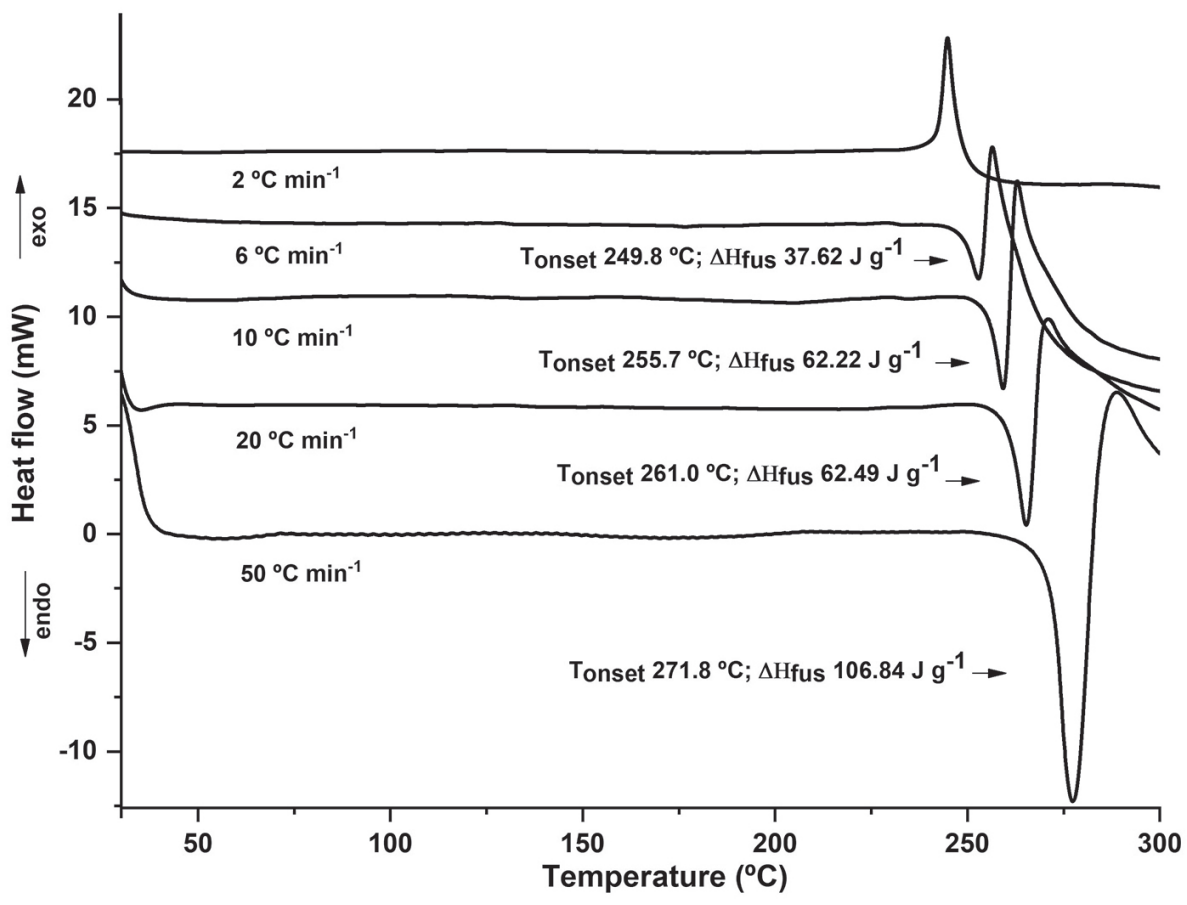

Figure 6. Differential scanning calorimetry curves of azathioprine (AZA) at heating rates of 2, 6, 10, 20, and $50{ }^{\circ} \mathrm{C} \mathrm{min}^{-1}$. 
Marques et al. ${ }^{25}$ The authors described the influence of the heating rate and the sample amount into the evaluation of the thermal behavior for the atorvastatin trihydrate calcium and furosemide system. As observed for 10 and $20^{\circ} \mathrm{C} \mathrm{min}{ }^{-1}$, the heat fusion is approximately the same, differently from the value found at $6{ }^{\circ} \mathrm{C} \mathrm{min}-1$. According to these results, the adopted heating rate was $10^{\circ} \mathrm{C} \mathrm{min}-1$, corresponding to the lower stable heating rate for the studied system.

DSC evaluates the compatibility of AZA with the excipients for tablet dosage oral. Melting points shifts identifies interaction, as well as changes in the thermal phenomenon shape or area, the appearance of a transition, and an increase or decrease in the number of peaks, usually considered as pieces of evidence of interaction. ${ }^{6,15,44}$

Figure 7 shows the DSC curves of AZA, ST, $\mathrm{SiO}_{2} \mathrm{c}$, TA (black), and the binary mixtures (blue). The observed endothermic peak in the DSC curve of AZA refers to melting, as previously discussed, at $\mathrm{T}_{\text {onset }}=255.7{ }^{\circ} \mathrm{C}$, $\Delta \mathrm{H}_{\text {fus }}=62.22 \mathrm{~J} \mathrm{~g}^{-1}$ (used standard assess the incompatibility between AZA and excipients, in case of displacement or disappearance of the phenomenon, dotted line). DSC curve of ST shows a broad endothermic peak between 30 and $130{ }^{\circ} \mathrm{C}$, characteristic of sample dehydration as described by Cordoba et al. ${ }^{45}$ It exhibits thermal stability up to ca. $280{ }^{\circ} \mathrm{C}$, phenomena confirmed by $\mathrm{TG}$ (data not shown). In the DSC curve of the AZA + ST binary mixture, it is possible to observe the melting at $254.80{ }^{\circ} \mathrm{C}$; no other thermal events are identified, suggesting compatibility between the drug and ST. $\mathrm{SiO}_{2} \mathrm{c}$ does not exhibit heat flow modifications within the analyzed range. In the $\mathrm{AZA}+\mathrm{SiO}_{2} \mathrm{c}$ binary mixture, AZA melting occurs at $\mathrm{T}_{\text {onset }}=257.40{ }^{\circ} \mathrm{C}$, showing $88 \%$ lower enthalpy $\left(\Delta \mathrm{H}_{\text {fus }}=5.7 \mathrm{~J} \mathrm{~g}^{-1}\right)$, the explanation is that part of the sample did not melt due to the thermal protection given by $\mathrm{SiO}_{2} \mathrm{C}$ already observed by Rowe et al. ${ }^{22}$ Matos et al.${ }^{46}$ studied the compatibility between diazepam and $\mathrm{SiO}_{2} \mathrm{c}$. They obtained similar results, protection from the $\mathrm{SiO}_{2} \mathrm{c}$, a refractory material, able to absorb part of the energy in the atom, and lattice vibrations. The melting temperature of diazepam in the binary mixture was unchanged, but the associated enthalpy was $30 \%$ lower. ${ }^{46}$ TA did not exhibit enthalpy changes between 30 and $300{ }^{\circ} \mathrm{C}$ for the magnesium silicate. DSC curves of AZA + TA binary mixtures show the API melting at $254.9^{\circ} \mathrm{C}$ and $\Delta \mathrm{H}_{\text {fus }}=39.72 \mathrm{~J} \mathrm{~g}^{-1}, 31 \%$ lower than expected, for the same reason as already described for $\mathrm{SiO}_{2} \mathrm{c}$ and found by Rowe et al. ${ }^{22}$ Together, those results show that the excipients $\mathrm{ST}, \mathrm{SiO}_{2} \mathrm{c}$, TA are fully compatible with AZA, even under heat supply.

On the other hand, MA, SA, and MS (Figure 7, black curves) show modifications to the thermal behavior of AZA for the physical mixture (Figure 7, red curves). The DSC curve for MA presented an endothermic event, not

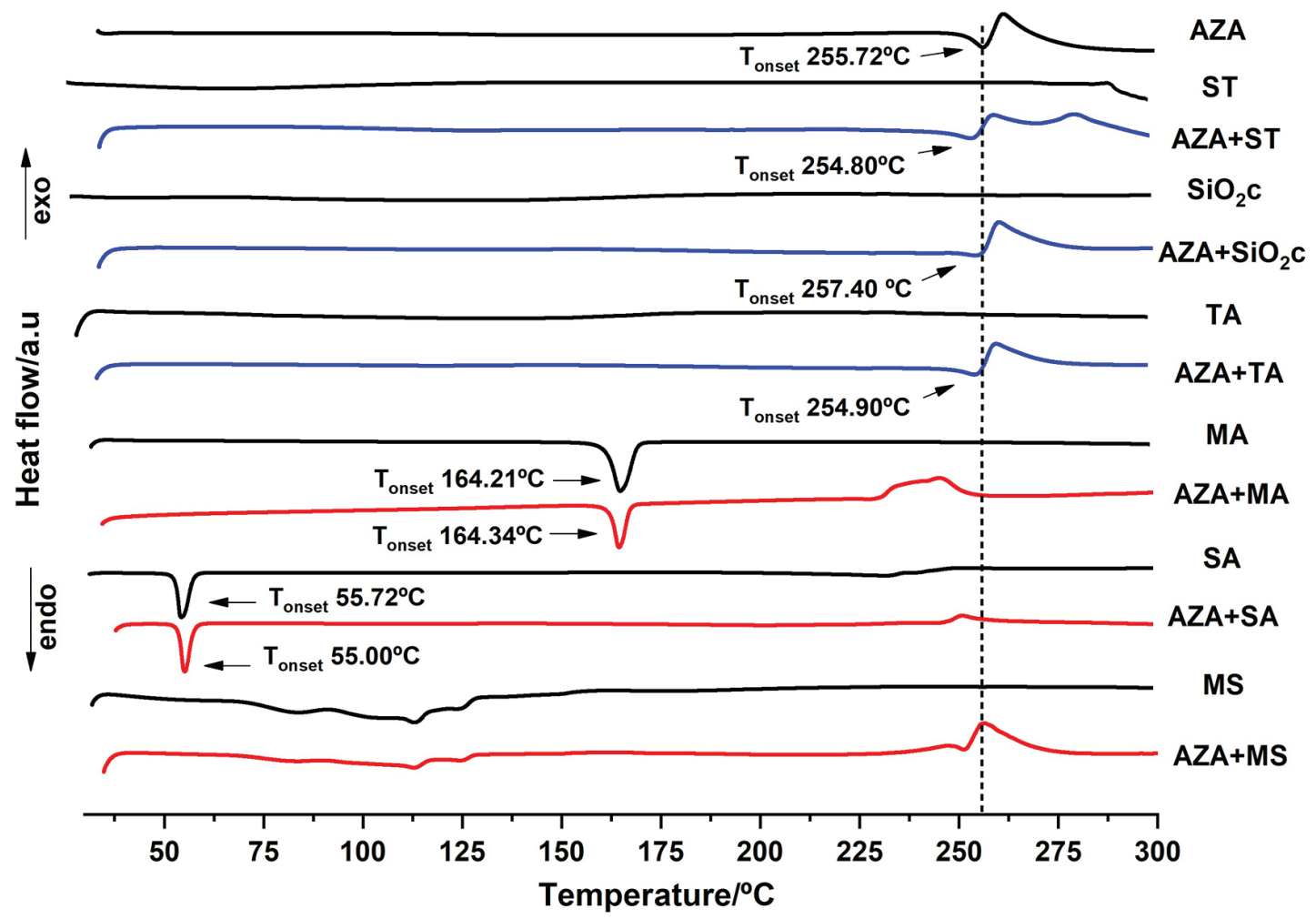

Figure 7. Differential scanning calorimetry curves of azathioprine $(\mathrm{AZA})$, starch $(\mathrm{ST}), \mathrm{AZA}+\mathrm{ST}$ binary, colloidal silicon dioxide $\left(\mathrm{SiO}_{2} \mathrm{c}\right), \mathrm{AZA}+\mathrm{SiO}_{2} \mathrm{c}$ binary, talc (TA), AZA + TA binary, mannitol (MA), AZA + MA binary, stearic acid (SA), AZA + SA binary, magnesium stearate (MS), AZA + MS binary. 
followed by a mass loss in the TG curve (data not shown), which indicates a physical phenomenon related to melting $\left(\mathrm{T}_{\text {onset }}=164.2{ }^{\circ} \mathrm{C}, \Delta \mathrm{H}_{\text {fus }}=311 \mathrm{~J} \mathrm{~g}^{-1}\right)$. In the AZA + MA mixture, the melting of MA $\left(\mathrm{T}_{\text {onset }}=164.3{ }^{\circ} \mathrm{C}\right)$ occurs, but no observable fusion of AZA is present. From $228^{\circ} \mathrm{C}$ there is an exothermic decomposition confirmed by mass loss in the TG curve (data not shown). Melting endotherm event is observed for $\mathrm{SA}\left(\mathrm{T}_{\text {onset }}=55.7^{\circ} \mathrm{C}\right)$, and in the AZA + SA curve $\left(\mathrm{T}_{\text {onset }}=55.0^{\circ} \mathrm{C}\right)$. In this case, there is no observed melting event for the drug inside the mixture. The mixtures incompatibility between AZA-MA and AZA-SA may be explained by the partial physical solubilization of the drug, occurring into the molted excipient before the degradation of the sample. Between 65 and $131{ }^{\circ} \mathrm{C}$, MS undergoes several, and in sequence, endothermic events, attributed to dehydration and fusion of the sample. ${ }^{47}$ For the AZA + MS binary, DSC curve exhibits the same endotherm of MS and another peak at $\mathrm{T}_{\text {onset }}=254{ }^{\circ} \mathrm{C}$, attributed to the AZA melting, but with an enthalpy of $1.22 \mathrm{~J} \mathrm{~g}^{-1}$, about $2 \%$ of the expected value, indicating that this signal refers to the fusion of remaining AZA, which did not interact with MS with heat supply. Incompatibility between MS and other active pharmaceutical ingredients are already known. ${ }^{11,48}$ Jaminet and Louis ${ }^{49}$ described the presence of magnesium oxide as an impurity in MS that could catalyze degradation reactions by creating an alkaline medium upon contact with moisture. Cheng et al. ${ }^{50}$ and Stulzer et al. ${ }^{51}$ described interactions between captopril and the MS carboxylate group, characterizing the incompatibility. Thus, MA, SA, MS were the excipients incompatible with AZA at the heat supply, fundamental aspect to be considered in the pharmacotechnical development and product quality review periodical of AZA tablets since unit operations sometimes require or in general, generate heat. ${ }^{1,9,52}$

TG curves of incompatible mixtures showed a reduction in the thermal stability of AZA in the presence of such excipients (Figure 8).

Aiming to explore the influence of MA, SA, and MS on the AZA thermal stability, nonisothermal decomposition data were treated by the nonlinear Vyazovkin method in the kinetics studies. ${ }^{53,54}$ This isoconversional method is widely used. ${ }^{24,26,55}$ For the AZA + MA system, the decomposition process was considered as a single step, while for the AZA, $\mathrm{AZA}+\mathrm{SA}$ and AZA + MS systems, regarded as a double step process, as can be verified in the mass loss profile of experimental TG curves.

The measured nonisothermal TG experimental data use four heating rates: $6,8,10$ and $12{ }^{\circ} \mathrm{C} \mathrm{min}-1$ for all studied systems. Figure 9 a shows the entire thermal decomposition for AZA system $(0<\alpha<1)$ and Figures $9 \mathrm{~b}, 0<\alpha<0.5$, and $9 \mathrm{c}, 0.5<\alpha<1$, being the process divided into two events.

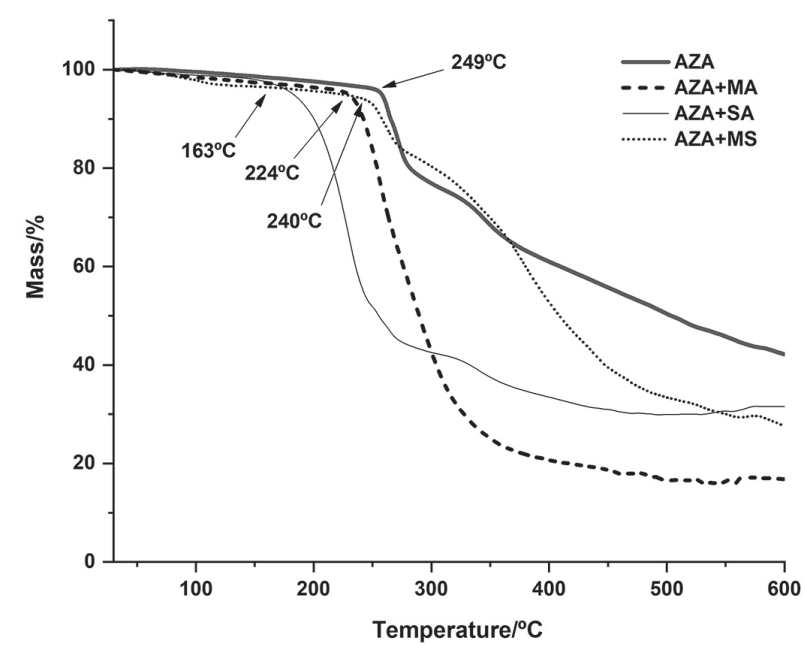

Figure 8. Thermogravimetry curves of azathioprine (AZA), AZA + mannitol (AZA + MA) binary, AZA + stearic acid (AZA + SA) binary, AZA + magnesium stearate $(\mathrm{AZA}+\mathrm{MS})$ binary, under a dynamic

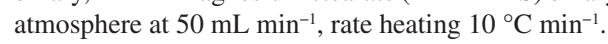

At $\alpha=0.5$, there is a discontinuity in the sigmoid in all dynamic curves, indicating that the phenomenon presents different behaviors before and after $\alpha=0.5$.

For the AZA + MA system, thermal decomposition occurs in a single step, as shown in Figure 10.

For the AZA + SA system, the thermal decomposition process remains divided into two steps at $\alpha=0.75$. The experimental curves are in Figure 11. Similarly to the behavior observed in AZA dynamic curves (Figure 9), there is at $\alpha=0.75$ a discontinuity in the sigmoid in all dynamic curves, indicating the phenomenon presents different behaviors between $0<\alpha<0.75$ and $0.75<\alpha<1$.

The system AZA + MS also shows two events in their thermal decomposition, shown in Figure 12. As observed in the behavior of the dynamic curves of AZA (Figure 9) and AZA + MA (Figure 11), there is at $\alpha=0.25$ a discontinuity in the sigmoid in all dynamic curves, indicating the phenomenon presents different behaviors between $0<\alpha<0.25$ and $0.25<\alpha<1$.

The activation energies calculated by the Vyazovkin method for all studied systems are summarized in Table 1. As can be noted, the systems AZA, AZA + MA, and $\mathrm{AZA}+\mathrm{MS}$ present a similar behavior, i.e., the activation energy decreases along the decomposition process, reaching a minimum value and then shows a subsequent enhancement, as a minimum function. This behavior indicates that these systems decompose to a product that is more unstable than the original material, as smaller energy must proceed with the decomposition process. After the minimum point, it is possible to suggest some molecular rearrangement, with a tridimensional structure more difficult to decompose, as the activation energy increases until the complete decomposition. 


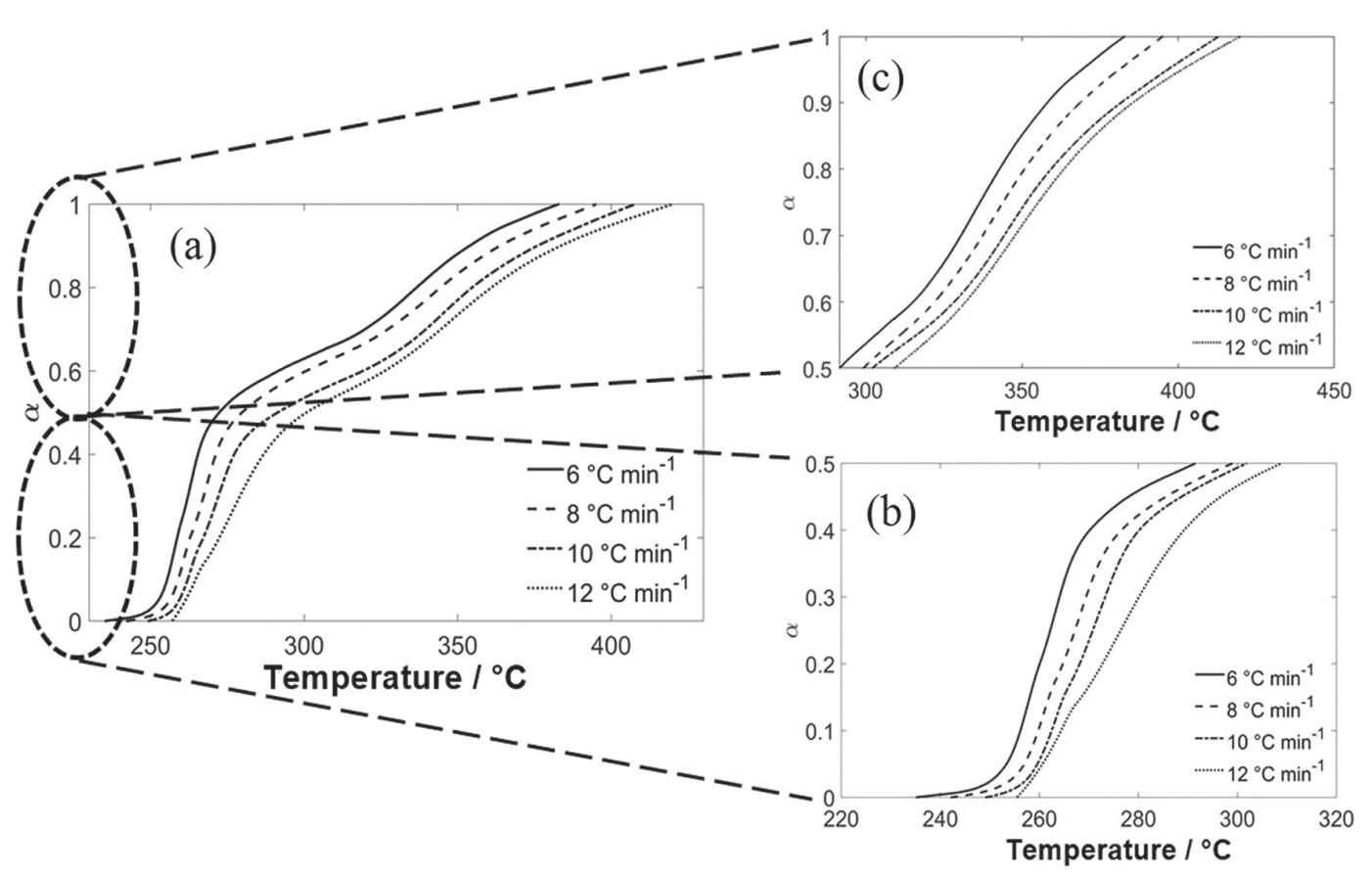

Figure 9. Experimental data of the decomposition fraction, $\alpha$, for azathioprine showing the (a) complete phenomenon $(0<\alpha<1)$ and the two steps of the phenomenon between (b) $0<\alpha<0.5$ and (c) $0.5<\alpha<1$.

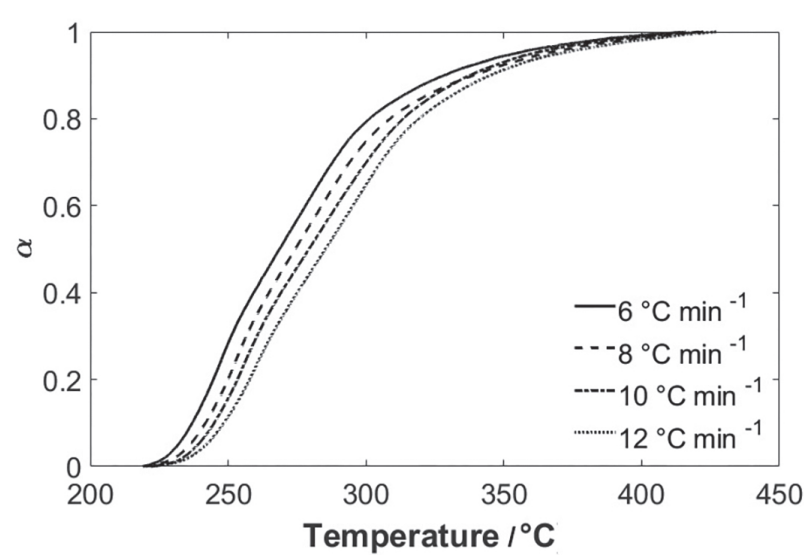

Figure 10. Experimental data of the decomposition fraction, $\alpha$, for azathioprine and mannitol (AZA + MA).

The AZA + SA system presents a different behavior, similar to a maximum function. The activation energy increases until the material reaches $50 \%$ of the decomposition, with the products more stable than the original system. The observation is explained by an internal tridimensional arrangement, producing an intermediate specie in the reaction with more strong bonds or interactions.

The standard deviation for Vyazovkin's method is present in Table 1. The small values for standard deviation, the maximum amount of $1 \%$, confirm the methodology as an appropriate tool to investigate the kinetic events in all studied systems.

Based on the described results, it is noticeable that the SA drastically reduce the thermal stability of AZA from $249^{\circ} \mathrm{C}\left(\mathrm{Ea}=175 \mathrm{~kJ} \mathrm{~mol}^{-1}\right)$, down to $163^{\circ} \mathrm{C}$ in the $\mathrm{AZA}+\mathrm{SA}$ mixture, having the necessary Ea to decompose $75 \%$ of the system $(\alpha=0.75)$ of about $65 \mathrm{~kJ} \mathrm{~mol}^{-1}$. It was the lowest Ea found, suggesting higher thermal lability, probably due to the acid-base reaction between the two components favored by heat. For AZA + MA, the temperature and necessary Ea to decompose the system also decreased down to $224{ }^{\circ} \mathrm{C}$ and $145 \mathrm{~kJ} \mathrm{~mol}^{-1}$, respectively. The presence of MS slightly reduced the thermal stability of the AZA + MS system from $249{ }^{\circ} \mathrm{C}$ down to $240{ }^{\circ} \mathrm{C}$. However, it requires higher Ea $\left(230 \mathrm{~kJ} \mathrm{~mol}^{-1}\right)$ to initiate $25 \%$ of the phenomenon $(\alpha=0.25)$. The MS presence explains this behavior. It is a large C18 aliphatic organic chain that recovers the AZA particles. At the heating supply, it acts as a heat shield undergoing fusion in the first place. That melted deposit over the AZA core particle slightly decreases the AZA thermal stability down to $240^{\circ} \mathrm{C}$, at the same time, to overcome the temperature gradient from outside to the AZA core, more Ea is necessary to start the process, $230 \mathrm{~kJ} \mathrm{~mol}^{-1}$. Figure 13 resumes the observed interdependence of temperature and $\mathrm{Ea}$ as a function of the binary and the values.

The study indicates that MA, SA, and MS excipients modify AZA solid-state properties, as also confirmed by DSC results. FTIR analysis also showed changes between the $3400-3100 \mathrm{~cm}^{-1}$ bands of the AZA + mannitol binary system (Figure 2).

The employed orbital theory of Kenichi Fukui ${ }^{56}$ helps in the understanding of the behavior of the AZA + MA system, considering the chemical tendency of reaction 


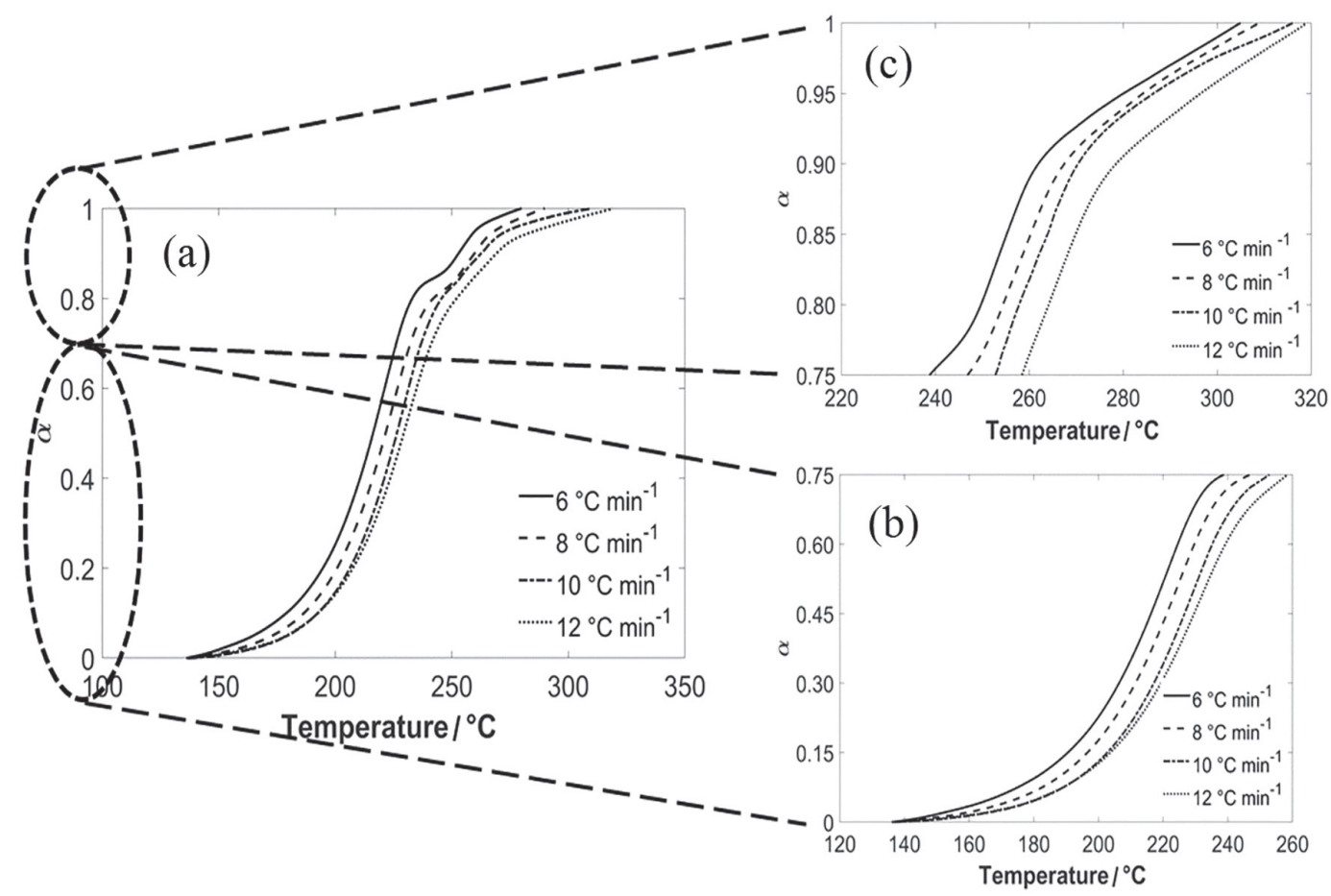

Figure 11. Experimental data of the decomposition fraction, $\alpha$, for azathioprine and stearic acid (AZA + SA) showing the (a) complete phenomenon $(0<\alpha<1)$ and the two parts of the phenomenon between (b) $0<\alpha<0.75$ and (c) $0.75<\alpha<1$.

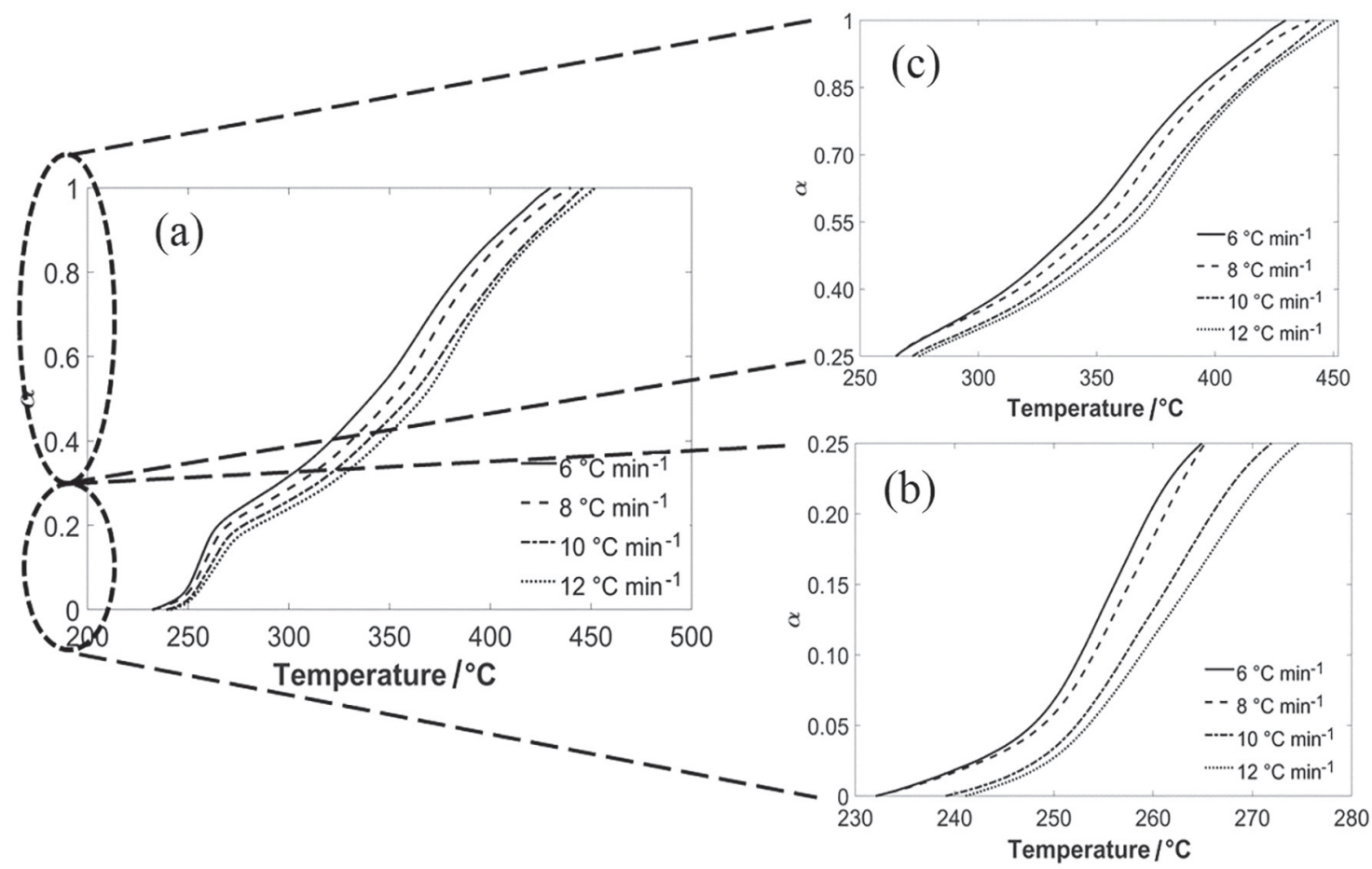

Figure 12. Experimental data of the decomposition fraction, $\alpha$, for azathioprine and magnesium stearate (AZA + MS) showing the (a) complete phenomenon $(0<\alpha<1)$ and the two parts of the phenomenon between (b) $0<\alpha<0.25$ and (c) $0.25<\alpha<1$.

between AZA + MA. Several author ${ }^{56-59}$ have tried to assess the reactivity of chemical species based on their intrinsic electronic properties. This methodology also determines chemical potential, hardness, softness, and reactivity index using theories as free valency, atomic charge computation, and spin populations. Parr and Weitao ${ }^{56}$ developed a successful method, the orbital theory of Kenichi Fukui. The Fukui functions relate to the affinity of a specific molecule to deal with the electrophilic and nucleophilic attack to its charge density. ${ }^{60}$ 
Table 1. Activation energy (Ea) \pm standard deviation for thermal decomposition of azathioprine (AZA), azathioprine and mannitol (AZA + MA), azathioprine and stearic acid (AZA + SA) and azathioprine and magnesium stearate (AZA + MS) as a function of conversion degree $(\alpha)$

\begin{tabular}{|c|c|c|c|c|c|c|c|}
\hline \multirow{3}{*}{$\alpha / \%$} & \multicolumn{7}{|c|}{$\mathrm{Ea} /\left(\mathrm{kJ} \mathrm{mol}^{-1}\right)$} \\
\hline & \multicolumn{2}{|c|}{ AZA } & \multirow{2}{*}{$\mathrm{AZA}+\mathrm{MA}$} & \multicolumn{2}{|c|}{$\mathrm{AZA}+\mathrm{SA}$} & \multicolumn{2}{|c|}{$\mathrm{AZA}+\mathrm{MS}$} \\
\hline & Event 1 & Event 2 & & Event 1 & Event 2 & Event 1 & Event 2 \\
\hline 1 & $106.70 \pm 0.0171$ & - & $184.95 \pm 0.0082$ & $78.60 \pm 0.1005$ & - & $124.75 \pm 0.1021$ & - \\
\hline 5 & $174.80 \pm 0.0116$ & - & $143.80 \pm 0.0006$ & $65.33 \pm 0.0515$ & - & $226.97 \pm 0.0945$ & - \\
\hline 10 & $169.95 \pm 0.0123$ & - & $130.01 \pm 0.0013$ & $74.93 \pm 0.0454$ & - & $173.96 \pm 0.0801$ & - \\
\hline 20 & $114.94 \pm 0.0014$ & - & $116.81 \pm 0.0032$ & $89.56 \pm 0.0242$ & - & $81.71 \pm 0.0433$ & - \\
\hline 30 & $94.69 \pm 0.0046$ & - & $108.99 \pm 0.0049$ & $96.64 \pm 0.0137$ & - & - & $68.61 \pm 0.0048$ \\
\hline 40 & $74.68 \pm 0.0067$ & - & $102.60 \pm 0.0077$ & $100.12 \pm 0.0083$ & - & - & $79.06 \pm 0.0034$ \\
\hline 50 & - & $56.14 \pm 0.0025$ & $99.82 \pm 0.0064$ & $101.74 \pm 0.0058$ & - & - & $81.09 \pm 0.0077$ \\
\hline 60 & - & $46.32 \pm 0.0040$ & $100.03 \pm 0.0047$ & $100.80 \pm 0.0042$ & - & - & $93.46 \pm 0.0204$ \\
\hline 70 & - & $73.63 \pm 0.0080$ & $100.66 \pm 0.0016$ & $94.39 \pm 0.0032$ & - & - & $97.59 \pm 0.0327$ \\
\hline 80 & - & $82.33 \pm 0.0132$ & $106.06 \pm 0.0021$ & - & $78.27 \pm 0.0027$ & - & $99.85 \pm 0.0363$ \\
\hline 90 & - & $71.63 \pm 0.0131$ & $117.82 \pm 0.0935$ & - & $99.61 \pm 0.0039$ & - & $108.05 \pm 0.0285$ \\
\hline
\end{tabular}

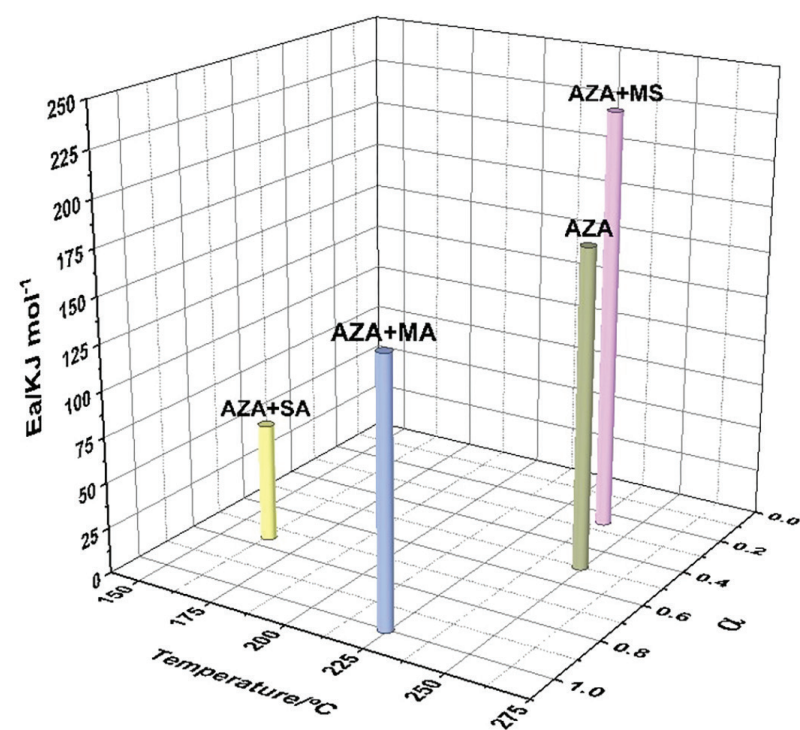

Figure 13. Activation energy (Ea) of the thermal decomposition process, initial temperature and the correponding degree of conversion $(\alpha)$ for azathioprine (AZA, green), AZA + mannitol (AZA + MA, blue) binary, $\mathrm{AZA}+$ stearic acid (AZA + SA, yellow) binary, AZA + magnesium stearate (AZA + MS, pink) binary.

By using a numerical integration procedure such as a Hirshfeld surface analysis, more quantitative predictions are possible to be addressed from the condensed Fukui functions for any atom in the molecule.

Figure 14 displays the Kenichi Fukui functions for AZA. It shows that the high probability sites for a radical attack are still restricted to a lattice plan containing the sulfur atom. By the structure inspection, the probability is moderated by the confined space, turning it in an unlikely pathway. An electrophilic attack would be unfavorable due to the electron density of the molecules, high electron density centers such as nitrogen, sulfur, and oxygen atoms. The most probable pathway of any reaction would be a nucleophilic attack, showing a large probability surface of reactivity.

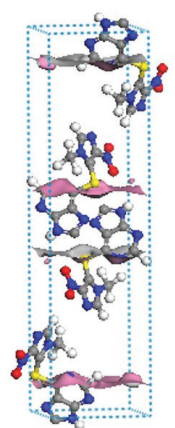

(a)

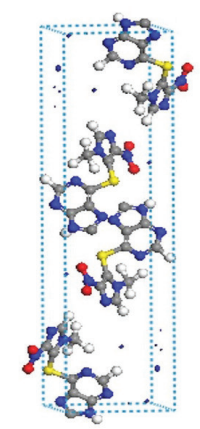

(b)

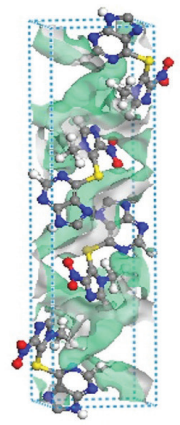

(c)

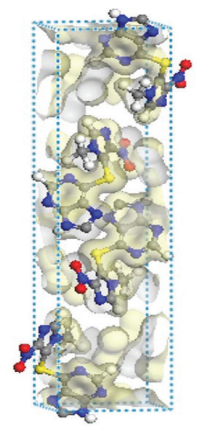

(d)
Figure 14. Kenichi Fukui functions for azathioprine, $f(0)$ standing for a probability surface of reactivity with a radical attack (a); probability surface of responsiveness with an electrophilic attack (b); probability surface of reactivity with a nucleophilic attack (c); and the total electron density surface as numerical integration from the Hirshfeld surface analysis (d).

Kenichi Fukui functions for MA are given in Figure 15. MA presents more exposed electron densities, being able to promote or receive electrons from any reaction. If externally altered by heating, after melting, their molecules may access electrons donors or acceptors at the AZA molecule. The higher reactive center is the $\mathrm{C}=\mathrm{O}$, the polarizable carboxyl group, sharing 3 electrons pairs in the carboxyl oxygen.

Compatibility studies investigate physical and chemical interactions between the drug and other components, attesting the stability of the formulation. The solid-state reactions may result in variations of the stability, solubility, 


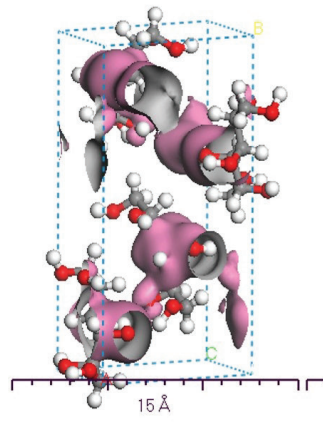

(a)

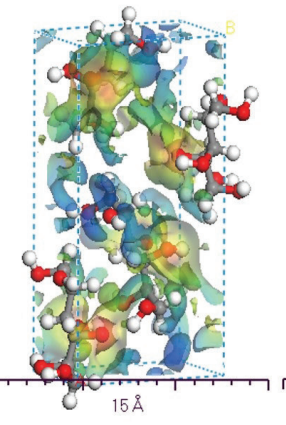

(b)

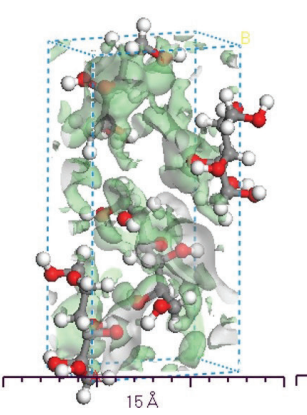

(c)

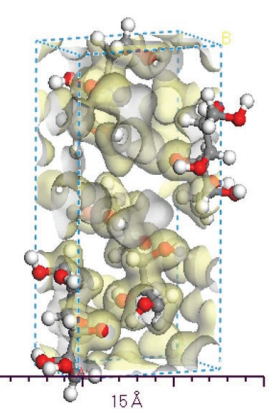

(d)

Figure 15. Kenichi Fukui functions for mannitol, $f(0)$ standing for a probability surface of reactivity with a radical attack (a); probability surface of responsiveness with an electrophilic attack (b); probability surface of reactivity with a nucleophilic attack (c); and the total electron density surface as numerical integration from the Hirshfeld surface analysis (d).

dissolution rates, bioavailability, and aspects related to pharmacotherapeutic efficacy. ${ }^{1,9}$

The significant above-described surfaces with highly reaction probabilities, expose the necessity of one preformulation step and product quality review as an essential part of the knowledge of the AZA physicochemical behavior, as well as the possible excipients candidates. The compatibility evaluation between the drug and components is critical as an integral part of the GMP. It is worth to be included in the product quality review. Therefore, further biopharmaceutical studies are necessary to assess the impact of this incompatibility between AZA and mannitol, stearic acid, and magnesium stearate in the organism's performance.

Fukui function may be used as an essential tool in surface reactions site probabilities, helping to a better understand of the overall system.

\section{Conclusions}

AZA's solid-state properties are essential to set the combination of drug and excipients of pharmaceutical interest along with the development of solid-solid drug delivery systems. FTIR and PXRD showed that AZA is compatible with all the studied excipients under static conditions. However, by applying heat supply, the DSC analysis indicates that the drug can solubilize in the molten excipient (mannitol, stearic acid, and magnesium stearate) at temperatures likely to be achieved during processing technology, indicating a potential incompatibility. The AZA's solid-state properties are modified by the excipients MA, SA and MS, as confirmed by DSC and TG results. The listed excipients are still widely used in the formulation of several drug tablets. Therefore, AZA solid-state transformations can impact the biopharmaceutical properties of the derived tablets. Thus, the evaluation of compatibility of the drug with the excipients is critical for product quality review due to established products with desirable pharmaceutical characteristics and bio-kinetics, along the shelf time.

\section{Acknowledgments}

This study was financed in part by the Coordenação de Aperfeiçoamento de Pessoal de Nível Superior, Brazil (CAPES), finance code 001. The authors also thank Conselho Nacional de Desenvolvimento Científico e Tecnológico (CNPq), Fundação de Amparo à Pesquisa do Estado de Minas Gerais (FAPEMIG) for financial support and Fundação Ezequiel Dias for samples donation.

\section{Author Contributions}

Carolina R. G. Silva was responsible for the conceptualization, investigation and writing original draft; Silvia L. Fialho and Jamile Barbosa for the funding acquisition; Bárbara C. R. Araújo for the formal analysis; Guilherme Carneiro for the visualization; Rita C. O. Sebastião for the formal analysis, writing review and editing; Wagner N. Mussel for the formal analysis, writing review and editing; Maria I. Yoshida for the conceptualization, formal analysis, investigation and project administration; Maria B. de Freitas-Marques for the conceptualization, formal analysis, investigation, validation, writing original draft, review and editing.

\section{References}

1. Aulton, M. E.; Taylor, K. M. G.; Aulton Delineamento de Formas Farmacêuticas, $8^{\text {th }}$ ed.; Elsevier: Porto Alegre, Brazil, 2016.

2. Pandit, D.; Deb, P. K.; Chadha, R. In Biomaterials and Bionanotechnology, $1^{\text {st }}$ ed.; Tekade, R., ed.; Academic Press: Cambridge, USA, 2019, ch. 1. 
3. Lindström-Gommers, L.; Mullin, T.; Clin. Pharmacol. Ther. 2019, 105, 926.

4. Guide to Good Manufacturing Practice for Medicinal Products Part I; available at https://picscheme.org/docview/2470, accessed in November 2020.

5. Regulska, K.; Regulski, M.; Paszun, S. K.; Wzgarda, A.; Niemier, B.; Niżnik, B.; Stanisz, B. J.; Arabian J. Chem. 2017, $10,378$.

6. Romani, L. F. A.; Yoshida, M. I.; Gomes, E. C. L.; Machado, R. R.; Rodrigues, F. F.; Coelho, M. M.; Oliveira, M. A.; FreitasMarques, M. B.; San Gil, R. A. S.; Mussel, W. N.; J. Pharm. Anal. 2018, 8, 103.

7. Aucamp, M.; Milne, M.; Eur. J. Pharm. Sci. 2019, 139, 105057.

8. http://antigo.anvisa.gov.br/documents/10181/5389382/\%286 \%29RDC_301_2019_COMP.pdf/7d991c04-e7a1-4957-aed53689c62913b2, accessed in November 2020.

9. Gibson, M.; Pharmaceutical Preformulation and Formulation: A Practical Guide from Candidate Drug Selection to Commercial Dosage Form; CRC Press: Boca Raton, USA, 2016.

10. Balestrieri, F.; Magrì, A. D.; Magrì, A. L.; Marini, D.; Sacchini, A.; Thermochim. Acta 1996, 285, 337.

11. da Silveira, L. M.; Fiorot, A. B.; Xavier, T. P.; Yoshida, M. I.; de Oliveira, M. A.; Eur. J. Pharm. Sci. 2018, 112, 146.

12. Giron, D.; J. Therm. Anal. Calorim. 2002, 68, 335.

13. Giron, D.; J. Pharm. Biomed. Anal. 1986, 4, 755.

14. Kaur, A.; Goindi, S.; Katare, O. P.; Thermochim. Acta 2016, 643, 23.

15. Oliveira, M. A.; Yoshida, M. I.; Gomes, E. C. L.; Mussel, W. N.; Soares, C. D. V.; Pianetti, G. A.; Quim. Nova 2011, 34, 1224.

16. Attia, A. K.; Abdel-Moety, M. M.; Abdel-Hamid, S. G.; Arabian J. Chem. 2017, 10, S334.

17. Ionashiro, M.; Giolito: Fundamentos da Termogravimetria e Análise Térmica Diferencial/Calorimetria Exploratória Diferencial; Giz: São Paulo, Brazil, 2004.

18. Ozawa, T.; Thermochim. Acta 2000, 355, 35.

19. Covaci, O.-I.; Samohvalov, D.; Manta, C.-M.; Buhalteanu, L.; Barbatu, A.; Baibarac, M.; Daescu, M.; Matea, A.; Gherca, D.; J. Mol. Struct. 2019, 1178, 702.

20. Elion, G. B.; Science 1989, 244, 41.

21. Huskisson, E. C.; Clin. Rheum. Dis. 1984, 10, 325.

22. Rowe, R. C.; Sheskey, P.; Quinn, M.; Handbook of Pharmaceutical Excipients, $6^{\text {th }}$ ed.; Libros DigitalesPharmaceutical Press: London, United Kingdom, 2009.

23. Vyazovkin, S.; Chrissafis, K.; Di Lorenzo, M. L.; Koga, N.; Pijolat, M.; Roduit, B.; Sbirrazzuoli, N.; Suñol, J. J.; Thermochim. Acta 2014, 590, 1.

24. Brito, L. G.; Leite, G. Q.; Duarte, F. Í. C.; Ostrosky, E. A.; Ferrari, M.; de Lima, A. A. N.; Nogueira, F. H. A.; Aragão, C. F. S.; Ferreira, B. D. L.; Marques, M. B. F.; J. Therm. Anal. Calorim. 2019, 138, 3715.
25. Marques, M. B. F.; de Araujo, B. C. R.; Sebastião, R. C. O.; Mussel, W. N.; Yoshida, M. I.; Thermochim. Acta 2019, 682, 178408.

26. Marques, M. B. F.; Araujo, B. C. R.; Fernandes, C.; Yoshida, M. I.; Mussel, W. N.; Sebastião, R. C. O.; J. Braz. Chem. Soc. 2020, 31, 512 .

27. Kissinger, H. E.; Anal. Chem. 1957, 29, 1702.

28. Ozawa, T.; Thermochim. Acta 1992, 203, 159.

29. Ozawa, T.; J. Therm. Anal. Calorim. 1970, 2, 301.

30. Vyazovkin, S.; Isoconversional Kinetics of Thermally Stimulated Processes; Springer: New York, USA, 2015.

31. Vyazovkin, S.; Dollimore, D.; J. Chem. Inf. Comput. Sci. 1996, 36,42 .

32. Hsieh, W.; Cheng, W.; Chen, L.; Lin, S.; Asian J. Pharm. Sci. 2018, 13, 212.

33. Rotaru, A.; Goşa, M.; J. Therm. Anal. Calorim. 2009, 97, 421.

34. Rotaru, A.; J. Therm. Anal. Calorim. 2016, 126, 919.

35. Sebastião, R. C. O.; Braga, J. P.; Yoshida, M. I.; J. Therm. Anal. Calorim. 2003, 74, 811.

36. ASTM E2550-17: Standard Test Method for Thermal Stability by Thermogravimetry; ASTM International: West Conshohocken, PA, 2017; available at https://www.astm.org/ Standards/E2550.htm, accessed in November 2020.

37. ASTM E537-12: Standard Test Method for Thermal Stability of Chemicals by Differential Scanning Calorimetry; ASTM International: West Conshohocken, PA, 2012; available at https://www.astm.org/Standards/E537.htm, accessed in November 2020.

38. Sarge, S.; Hemminger, W.; Gmelin, E.; Höhne, G.; Cammenga, H.; Eysel, W.; J. Therm. Anal. Calorim. 1997, 49, 1125.

39. Varsányi, G.; Láng, L.; Assignments for Vibrational Spectra of Seven Hundred Benzene Derivatives, vol. 2; Adam Hilger: London, UK, 1974.

40. Socrates, G.; Infrared and Raman Characteristic Group Frequencies: Tables and Charts; John Wiley \& Sons: New York, USA, 2004.

41. Girotra, P.; Singh, S. K.; Int. J. Pharm. Sci. Drug Res. 2013, 5 , 133.

42. Makhyoun, M. A.; Massoud, R. A.; Soliman, S. M.; Spectrochim. Acta, Part A 2013, 114, 394.

43. Cavalheiro, E. T. G.; Ionashiro, M.; Breviglieri, S. T.; Marino, G.; Chierice, G. O.; Quim. Nova 1995, 18, 305.

44. Mussel, V. A. F. S. N.; Ferreira, M. P.; Marques, M. B. F.; Yoshida, M. I.; Almeida, M. R.; Rodrigues, B. L.; Mussel, W. N.; J. Pharm. Anal. 2018, 8, 194.

45. Cordoba, L. P.; Ribeiro, L. S.; Rosa, L. S.; Lacerda, L. G.; Schnitzler, E.; Thermochim. Acta 2016, 642, 45.

46. Matos, A. P. S.; Costa, J. S.; Boniatti, J.; Seiceira, R. C.; Pitaluga, A.; Oliveira, D. L.; Viçosa, A. L.; Holandino, C.; J. Therm. Anal. Calorim. 2017, 127, 1675.

47. Ertel, K. D.; Carstensen, J. T.; Int. J. Pharm. 1988, 42, 171. 
48. Bharate, S. S.; Bharate, S. B.; Bajaj, A. N.; J. Excipients Food Chem. 2016, $1,1131$.

49. Jaminet, F.; Louis, G.; Pharm. Acta Helv. 1968, 43, 153.

50. Cheng, W.-T.; Wang, S.-L.; Lin, S.-Y.; J. Phys. Chem. Solids 2008, 69, 1007.

51. Stulzer, H.; Rodrigues, P.; Cardoso, T.; Matos, J.; Silva, M.; J. Therm. Anal. Calorim. 2008, 91, 323.

52. Descamps, M.; Disordered Pharmaceutical Materials; John Wiley \& Sons: New York, USA, 2016.

53. Vyazovkin, S.; Sbirrazzuoli, N.; Macromol. Rapid Commun. 2006, 27, 1515.

54. Vyazovkin, S.; Burnham, A. K.; Criado, J. M.; Pérez-Maqueda, L. A.; Popescu, C.; Sbirrazzuoli, N.; Thermochim. Acta 2011, 520,1 .

55. Ferreira, B. D. L.; Araújo, N. R. S.; Ligório, R. F.; Pujatti, F. J. P.; Mussel, W. N.; Yoshida, M. I.; Sebastião, R. C. O.; J. Therm. Anal. Calorim. 2018, 134, 773.
56. Parr, R. G.; Weitao, Y.; Density-Functional Theory of Atoms and Molecules, revised edition; Oxford University Press: New York, USA, 1994.

57. Mendoza-Huizar, L. H.; Acta Chim. Slov. 2014, 61, 694.

58. Zhang, Q.; Zheng, F.; Zhao, T.; Qu, X.; Aires-de-Sousa, J.; Mol. Inf. 2016, 35, 62.

59. Sethi, A.; Singh, R. P.; Pathak, R.; Shukla, D.; Yadav, P.; J. Mol. Struct. 2020, 1201, 127136.

60. Cramer, C. J.; Essentials of Computational Chemistry: Theories and Models, $2^{\text {nd }}$ ed.; John Wiley \& Sons: Chichester, England, 2004.

Submitted: August 6, 2020

Published online: November 9, 2020 